\title{
Use of shape-memory alloys in construction: a critical review
}

1 Wen-Shao Chang BSArch, MSArch, PhD Lecturer, BRE Centre for Innovative Construction Materials, University of Bath, Bath, UK (corresponding author: wsc22@bath.ac.uk)
2 Yoshikazu Araki PhD

Associate Professor, Department of Architecture, Kyoto University, Kyoto, Japan
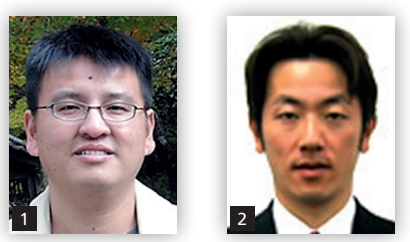

Shape-memory alloys possess a number of unique characteristics, such as shape memory and superelasticity. Shape memory means the alloys return to their original condition when heated, whereas superelasticity allows large deformations with limited or no residual strain. When the alloys repeatedly undergo phase transformation, they have superior energy dissipation capacity compared to normal metallic materials. Recent developments have been rapid, making the alloys a viable solution for numerous situations in buildings and infrastructure. This paper provides an overview of the potential and limitations of shapememory alloys in construction. First, applications in real projects are introduced and lessons learned are discussed. Second, the use of shape-memory alloys to mitigate natural disasters and enhance structural performance; to reduce vibration by increased damping; and to integrate into building envelopes to respond to the environment and improve energy efficiency are reviewed and discussed. Finally, factors that affect the shape-memory alloys used in construction are discussed.

\section{Introduction}

Shape-memory alloys are known to have two unique characteristics: a shape-memory effect and superelasticity. The shape-memory effect is the ability of the alloys to revert to their initial shape upon being heated until they enter their phase transformation temperature.

Superelasticity is where the alloys exhibit comparatively large recoverable strain. Different families of shape-memory alloys have different suitable applications due to their different ranges of transformation temperature, as depicted in Figure 1 (Omori et al., 2011). For example, aluminium-manganese and iron-nickelcobalt-aluminium shape-memory alloys are suitable for seismic application as their working temperatures cover the range of $-50^{\circ} \mathrm{C}$ to $50^{\circ} \mathrm{C}$.

Different families of shape-memory alloys have different advantages and disadvantages. Shape-memory alloys have been developed since the early 1960s. They have been successfully used for medical (Bansiddhi et al., 2008; Morgan, 2004; Sun et al., 2012), robotic (Kim et al., 2006; Qin et al., 2004; Wang et al., 2008), aerospace (Hartl and Lagoudas, 2007; Hartl et al., 2010a, 2010b) and automobile applications (Bellini et al., 2009; Stoeckel, 1990). This paper provides an overview on how shape-memory alloys can be used in buildings and infrastructure.

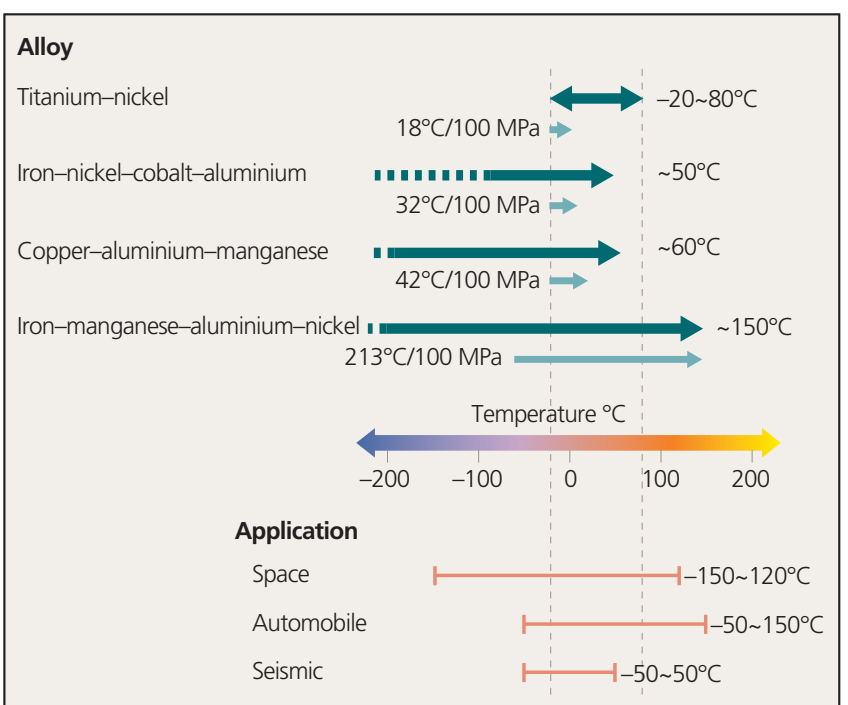

Figure 1. Operational temperature range of polycrystalline superelastic alloys with their applications (Omori et al., 2011) 


\section{Applications in construction to date}

The first field implementation using the shape-memory effect for post-tensioning of a concrete structure was on a highway bridge in Michigan. It had suffered cracks due to insufficient shear resistance. To strengthen the bridge girder, iron-manganesesilicon-chromium shape-memory alloy rods with a diameter of $10.4 \mathrm{~mm}$ were mounted crossing the cracks at both faces of the web (Figure 2). Each rod was heated by electrical power with $1000 \mathrm{~A}$ current to achieve $300^{\circ} \mathrm{C}$, resulting in a reduction of the crack width by $40 \%$ (Soroushian et al., 2001).

The lessons learned from the innovative project were: (1) a conventional hydraulic jack is an easier way to work on site if the purpose of the application is to provide force to close the crack in a structure; (2) the behaviour of shape-memory alloys under different working temperatures in the field needs to be investigated, in particular if the shape-memory alloys are to be left with the structures for a long time and the temperature fluctuates over time.

Shape-memory alloys have also been used to repair and strengthen architectural heritage structures. A shape-memory alloy device was developed by the EU-funded Istech project (Figure 3), which included nickel-titanium shape-memory alloy wires pre-tensioned within the device to ensure two-way superelasticity under movement. The ways shape-memory alloy devices were mounted within the structures depended on whether they were used to prevent large deformations of slender structures or out-of-plan collapse of building facades.

A number of shape-memory alloy devices were then implemented in the restoration of the bell tower of San Giorgio church at Trignano in Italy (Figure 4), which was heavily damaged by an earthquake in 1996. Shape-memory alloy devices were connected with steel bars in series inside the bell tower to restrain horizontal movement during an earthquake (Indirli and Castellano, 2008; Indirli et al., 2001a).

A similar application was then implemented to improve seismic performance of the bell tower of Badia Fiorentina in Italy (Figure 5) before an earthquake. It was strengthened by 18 shape-memory alloy devices in 2006. The devices were used in a similar way to those in Trignano. Although the devices cannot prevent the tower or a slender structure developing cracks during an earthquake, they can prevent the tower from having excessive deformation and, consequently, collapsing during aftershocks.

The technique was also applied at a number of Italian cultural heritage sites damaged by earthquakes to prevent collapse of

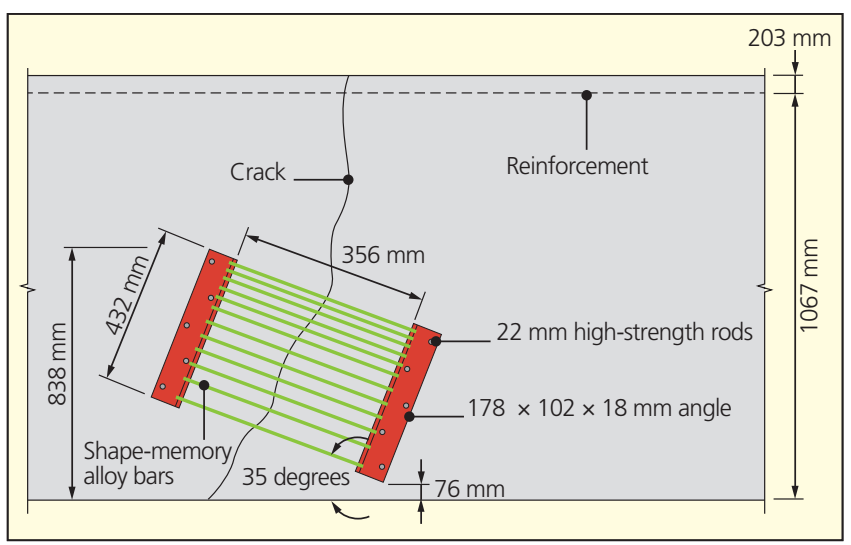

Figure 2. The shape-memory alloy bars were used to connect the two angles placed at both sides of the crack; the shape-memory effect would help to close the crack (Soroushian et al., 2001)

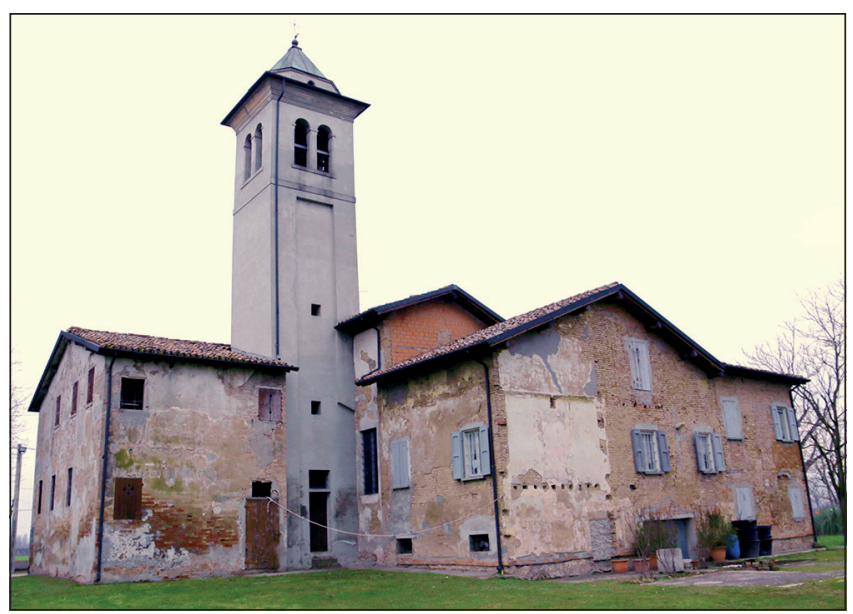

Figure 4. San Giorgio church and its bell tower, Trignano
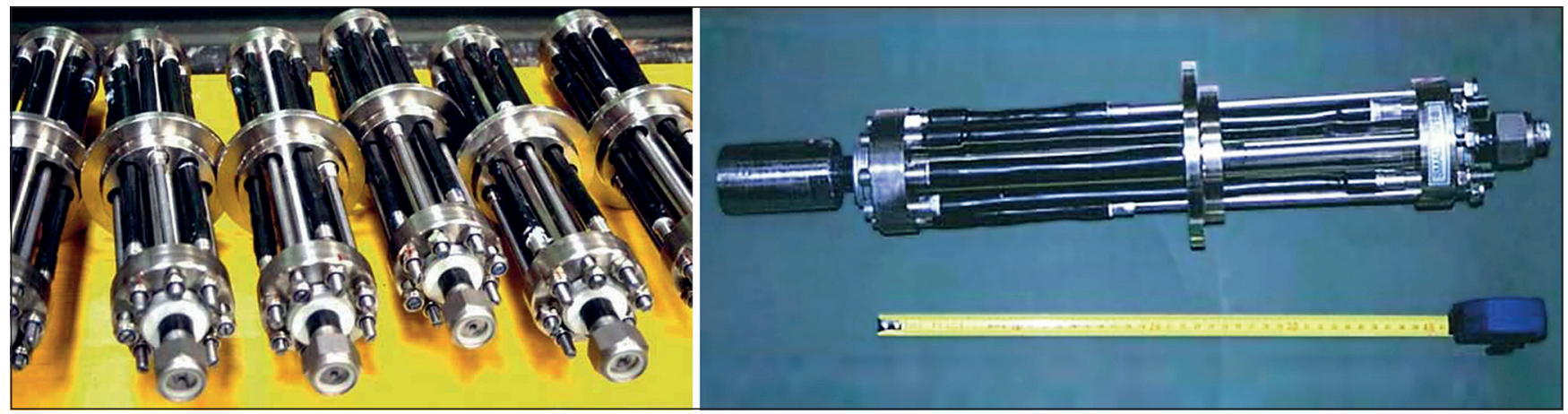

Figure 3. Shape-memory alloy device developed in Istech project (Indirli and Castellano, 2008) 


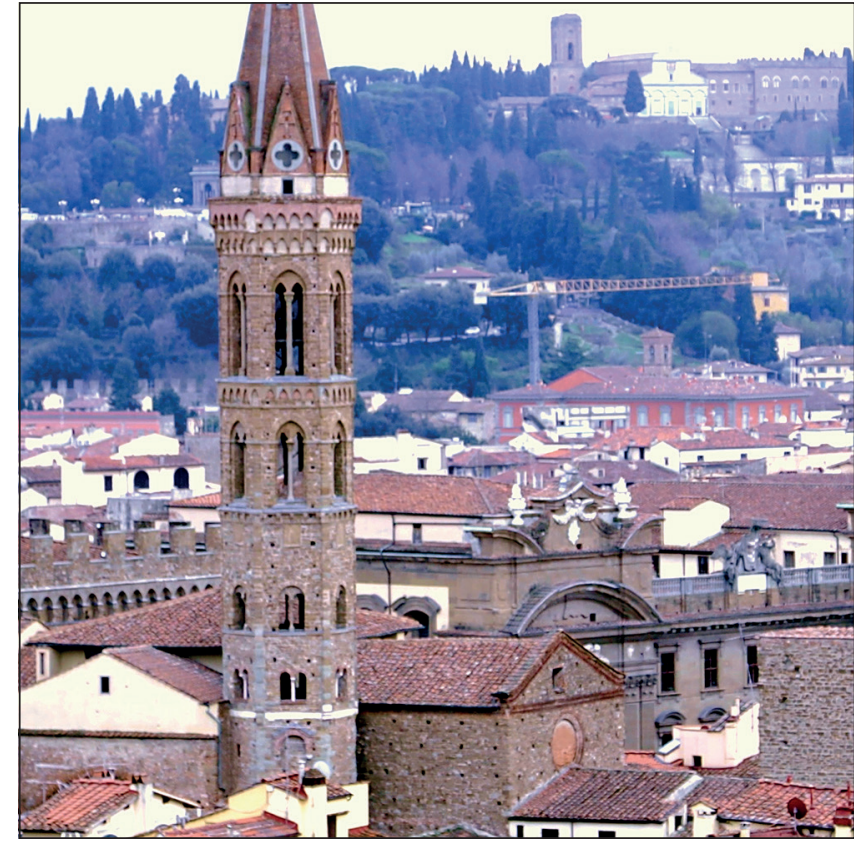

Figure 5. Bell tower of Badia Fiorentina, Firenze

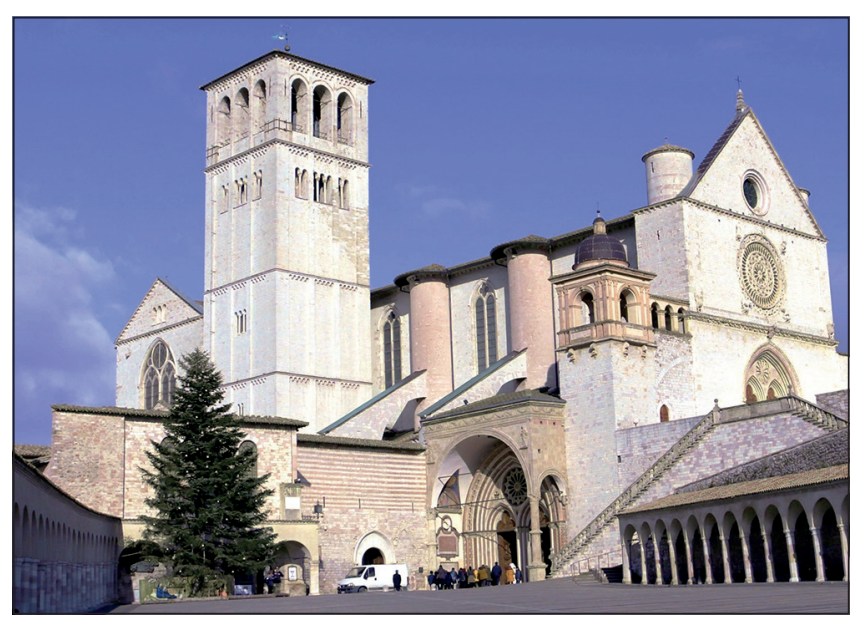

Figure 6. Basilica of St Francis, Assisi

facades, such as the Basilica of St Francis of Assisi (Figure 6) and the San Serafino church (Figure 7) (Indirli and Castellano, 2008, Indirli et al., 2001b). A total of 47 shape-memory alloy devices were installed to repair the facade of the Basilica of St Francis, which was damaged due to an earthquake in 1997 (Croci, 2001, Martelli, 2008). By 2008, at least 19 buildings were strengthened by shape-memory alloy devices or energy-dissipation systems (Benavent-Climent, 2008).

Experiences on these projects indicate that, compared with high damping capacity and shape-memory effect, superelasticity of shapememory alloys is extremely important when improving the structural behaviour in an earthquake or repairing mechanical damage of a structure after an earthquake, since damping can be provided by alternative mechanisms such as rubber or low-yield steel.

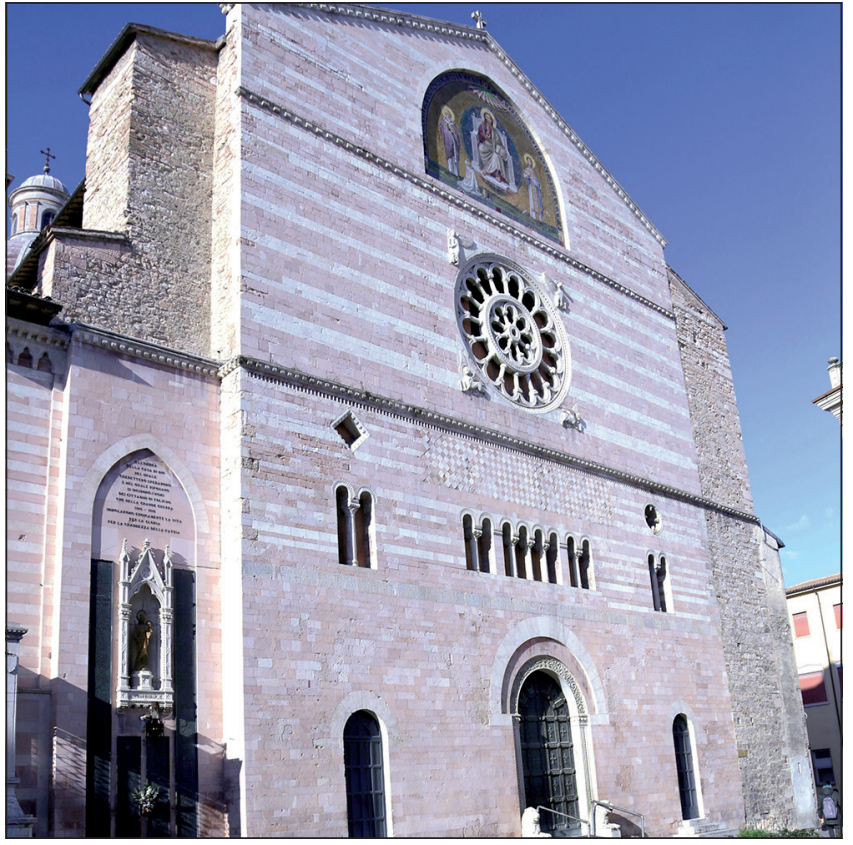

Figure 7. San Serafino church, Foligno

\section{Developments to improve seismic resistance}

Modern building codes require that structures undergo significant structural and/or non-structural damage so as to dissipate energy during a severe earthquake. After an earthquake, structures with large residual deformation are either repaired or demolished; therefore protection against economic loss is not guaranteed due to costs of repair and associated business downtime.

After the Christchurch, New Zealand earthquake in February 2011, approximately $50 \%$ of the buildings in the central business district were declared unusable due to their significant damage and nearly 1000 buildings were demolished. The estimated cost to New Zealand is about NZ\$40 billion, equivalent to $20 \%$ of the country's annual gross domestic product. This highlights a need for building systems that can dissipate energy with minimum structural damage and return to their initial position (self-centre) after earthquakes (Chancellor et al., 2014).

\subsection{Bridge restrainers}

Excessive movement in bridge supports, which leads to unseating of bridge decks, is a major cause of infrastructure failure during an earthquake (Andrawes and DesRoches, 2005). Reduction of the excessive movement of bridge decks relies on bridge restrainers.

Several bridge-restrainer systems incorporating shape-memory alloys have recently been developed: (a) nickel-titanium shapememory alloys in tension (Andrawes and DesRoches, 2005, 2007; Johnson et al., 2008); (b) nickel-titanium shape-memory alloys in bending (Choi et al., 2009); and (c) a hybrid system combining base isolation and shape-memory alloys (Ozbulut and Hurlebaus, 2010, 2011).

The experimental and analytical outcomes have revealed that bridge restrainers incorporating shape-memory alloys can reduce 
the movement of bridge decks during an earthquake and limit the residual deformation after an earthquake. However, the price of shape-memory alloys is the major barrier for them to be adopted, as most of the research work has been focused on nickel-titanium shape-memory alloys.

\subsection{Base-isolation systems}

A number of base-isolation systems have been developed using nickel-titanium shape-memory alloys (Dezfuli and Alam, 2013; Dolce et al., 2007; Wilde et al., 2000). All these systems were developed to combine a conventional rubber bearing system with shape-memory alloys, where the superelasticity of shape-memory alloys was exploited. The advantage of this combined system is that it can significantly reduce the movement of superstructures during an earthquake. After an earthquake, the superelasticity of the shape-memory alloys will bring the rubber bearing system back to its original position; however, during the earthquake large deformation was found in the base-isolation system.

To limit the large deformation of a conventional base-isolation system, Das and Mishra (2014) proposed a shape-memory alloy-rubber bearing (Figure 8) and demonstrated that it has better efficiency when compared against a conventional system. The disadvantage of this system is that it is more costly when the system is to be implemented in an existing structure, due to the cost of the material and construction.

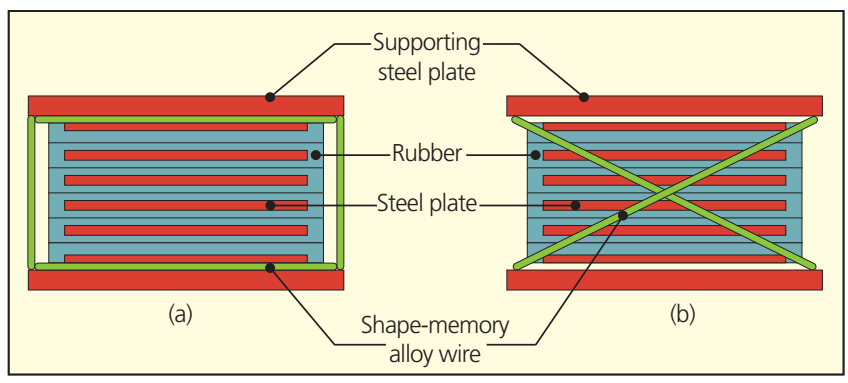

Figure 8. Details of shape-memory alloy-rubber bearing developed by Das and Mishra (2014)

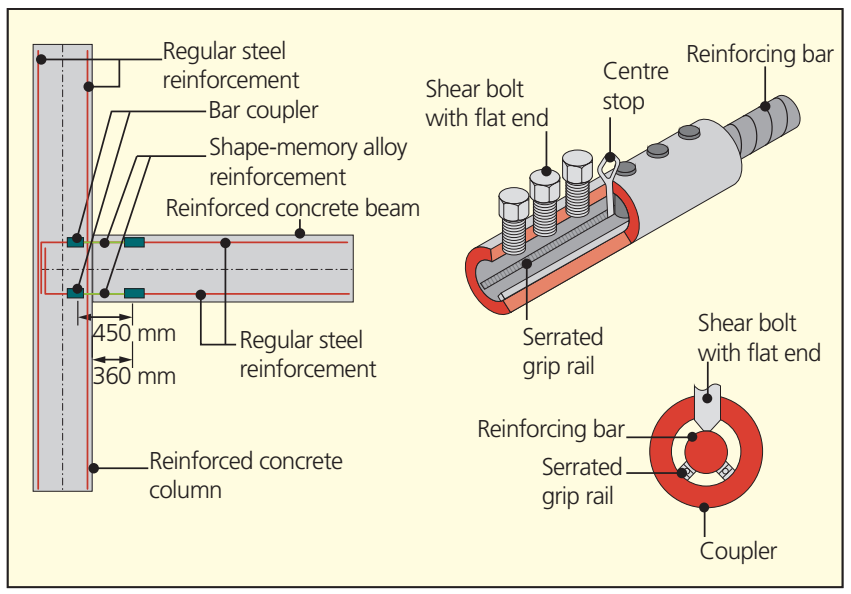

Figure 9. Concrete connection and single barrel screw-lock coupler with shape-memory alloys embedded (Alam et al., 2008)

\section{Embedding shape-memory alloys in structures}

\subsection{Concrete}

Several projects have been carried out using shape-memory alloys in a critical region of concrete structures where the main purpose is to reduce the permanent deformation (Saiidi and Wang, 2006). In an earthquake, shape-memory alloys are expected to yield in these regions and dissipate energy but also to recover the deformation. Shape-memory alloys can be used in concrete connections (Alam et al., 2008), as shown in Figure 9, and concrete beams (Abdulridha et al., 2013), as shown in Figure 10.

From hysteretic loops (shown in Figure 11) the shape-memory alloy bars can significantly reduce the residual deformation under both cyclic loading and reversed cyclic loadings. Notice that although the shape-memory alloys will yield during an earthquake, they will also facilitate the structure in recovering from deformation after an earthquake.

An alternative is to use shape-memory alloys in a shear wall; a series of tests have been performed and the results revealed that a shear wall with superelastic shape-memory alloy bar could reduce the residual displacement. However, it was also pointed out that the need to prevent buckling of shape-memory alloy bars needs to be investigated (Effendy et al., 2006).

The concrete part of the structure will remain damaged after the devastation; therefore the main advantage of this application is to reduce the repair cost as the shape-memory alloy performs superelasticity, which enables structures to have self-centre capacity.

\subsection{Steel and timber connections}

Attempts have been made to use shape-memory alloys in connections in timber (Chang et al., 2013) and steel connections (Abolmaali et al., 2006; Fang et al., 2014; Yam et al., 2015). DesRoches et al. (2010) pointed out that energy dissipating shapememory alloy connections are effective in reducing maximum deformation demands, while re-centring shape-memory alloy connections are more suitable for controlling residual deformation.

Conventional steel connections are often coupled with beam local buckling and are costly to repair after an earthquake; Ma et al. (2007) modified the connection with shape-memory alloy bolts to improve the solution, as shown in Figure 12, and have shown its effectiveness. Rofooei and Farhidzadeh (2011) analysed three-, six-, nine- and 12 -storey steel structures with $0,5 \%$,

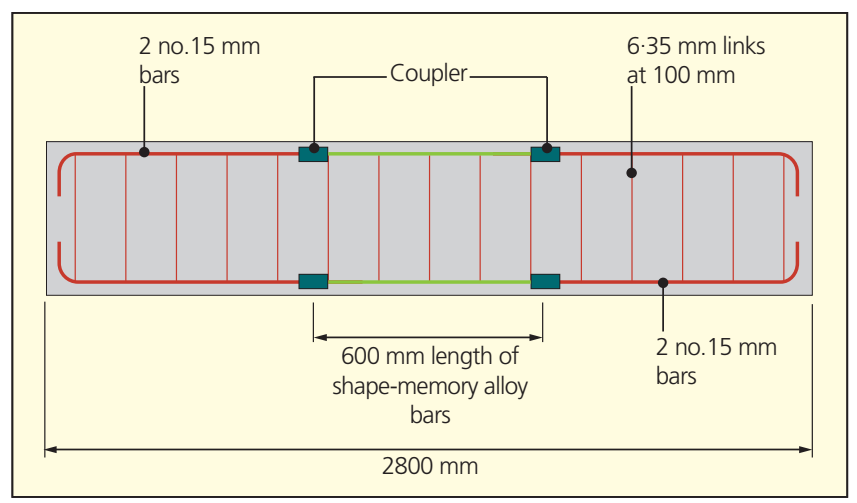

Figure 10. Beam specimen design (Abdulridha et al., 2013) 


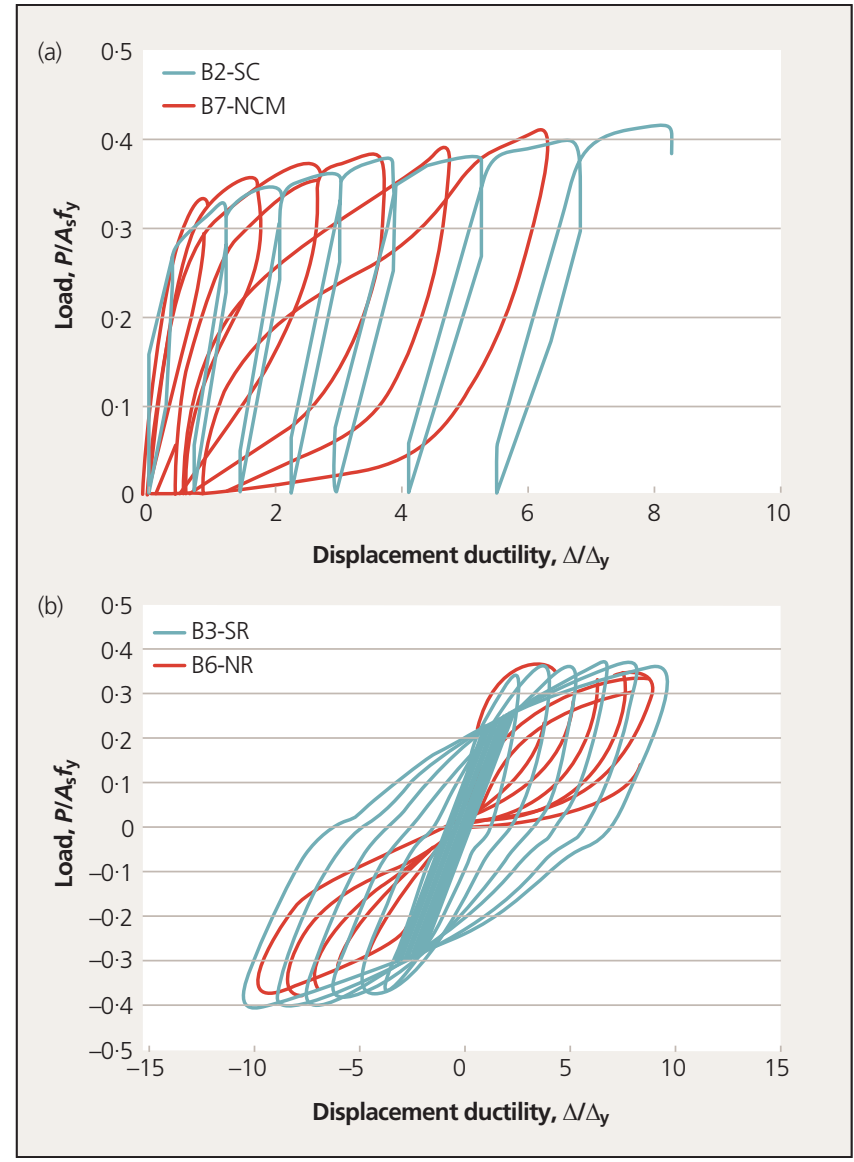

Figure 11. Normalised load-displacement ductility responses of concrete beam: (a) cyclic loading; (b) reversal cyclic loading (Abdulridha et al., 2013)

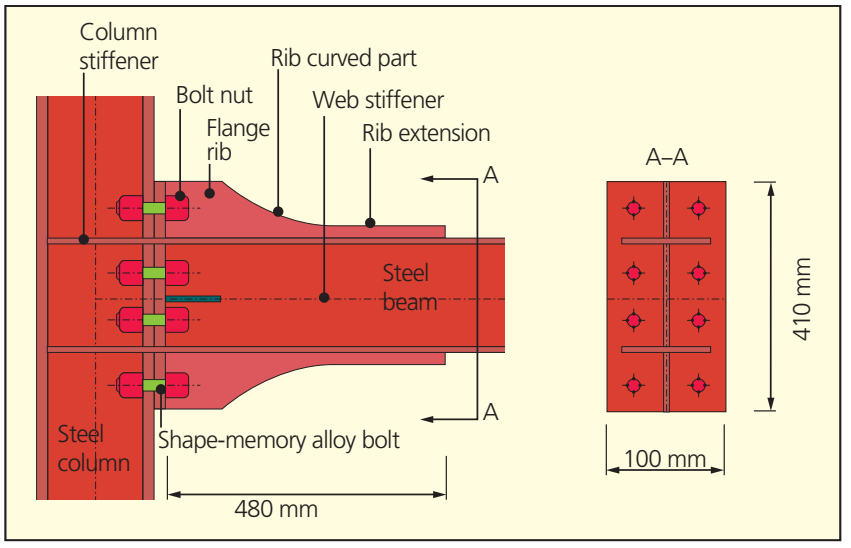

Figure 12. Steel beam-to-column connection with shape-memory alloy bolts (Ma et al., 2007)

$10 \%$, and $15 \%$ eccentricities, subjected to different bi-directional earthquake components using the connection designed by $\mathrm{Ma}$ et al. and compared the results with connections with normal bolts. The results showed that base shears were considerably reduced.

\subsection{Bracing}

Integration of shape-memory alloys in a bracing system can effectively resolve the pinching in the hysteretic loop of a structure after it undergoes a large deformation and demonstrates strong re-centring capacity (Araki et al., 2014; Hu et al., 2013; Massah and Dorvar, 2014), as illustrated in Figure 13.

Previous experiences with concentrically braced steel frames suggest that this system has limited ductility and energy dissipation due to buckling of the bracing. To tackle this limitation, several projects used shape-memory alloys connected with bracing of which the rigidity is much higher than that of shape-memory alloys.

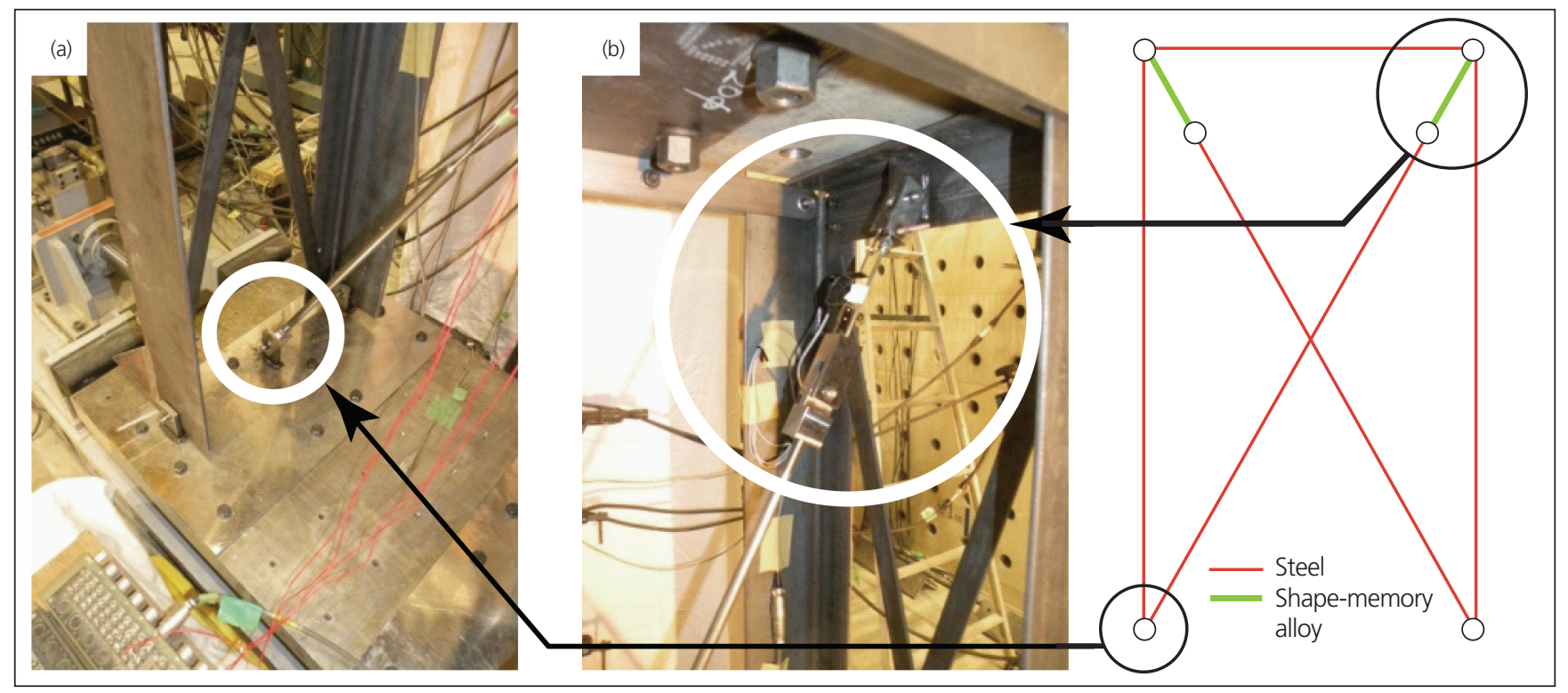

Figure 13. Bracing system design (Araki et al., 2014) 
Research has shown that braces with shape-memory alloys are effective in limiting inter-storey drifts and residual drifts during an earthquake (Auricchio et al., 2006; McCormick et al., 2007).

\section{Using shape-memory allows in building envelopes}

Shape-memory alloys can also contribute to the recent trend in adaptive buildings, enabling them to respond to changes in the ambient environment, such as changes in light, temperature and air quality.

A project 'Pixelskin02' by Sachin Anshuman in 2006 used shapememory alloy wires as a non-motorised technique for opening a facade. In this project, each pixel tile consisted of four triangular panels actuated by $200 \mathrm{~mA}$ shape-memory alloy wires and could open or close by controlling the electric current supply (Anshuman, 2008). Tashakori (2014) has also developed a computer-controlled facade system that can track the sun which employs shape-memory alloy wires, with the facade system actuated by providing electric current.

Coelho and Maes (2009) developed a shutter system that can control ventilation and light, motorised by shape-memory alloy wires. Loonen (2015) proposes using strips of shape-memory alloy that expand or contract in response to carbon dioxide concentration; thus a perfect balance between facade opening, pressure difference and momentary ventilation requirements can be achieved. Lignarolo et al. (2011) investigated the response of a kinetic facade to wind in tall buildings to enhance the aerodynamic behaviour of high-rise buildings; shapememory alloys were used to actuate deformation of the element in the facade and to change the roughness of the building skins.

Although many designers and architects are interested in developing systems composed of shape-memory alloys to make buildings respond to changes in the environment, the application of shape-memory alloys in building design is still in its infancy and at demonstration scale. More efforts are needed to ensure the market takes up the design in order to realise these concepts.

\section{Structural design considerations}

\subsection{Phase-transformation and working temperatures}

There are four critical phase-transformation temperatures: $M_{\mathrm{s}}, M_{\mathrm{f}}, A_{\mathrm{s}}$ and $A_{\mathrm{f}}$. They stand for the start (subscript s) and finish (subscript $\mathrm{f}$ ) temperatures of martensitic $(M)$ and austenitic $(A)$ transformations, respectively. The lattice of shape-memory alloy can transfer between twinned martensite, detwinned martensite and austenite with loading and temperature, as shown in Figure 14.

The superelasticity occurs when the working temperature is above $A_{\mathrm{f}}$. When the working temperature is below $A_{\mathrm{s}}$, the shapememory alloy will deform and could have permanent deformation before being heated. When the shape-memory alloy is heated to above $A_{\mathrm{f}}$, it will return to its original shape and the shape-memory effect will occur. Therefore, whether shape-memory alloys exhibit superelasticity or shape-memory effect depends on the working temperature in relation to these phase-transformation temperatures.

Although nickel-titanium shape-memory alloys have a superior superelasticity effect suitable for many applications in construction, there are limited possibilities in designing the $A_{\mathrm{f}}$ to achieve extremely

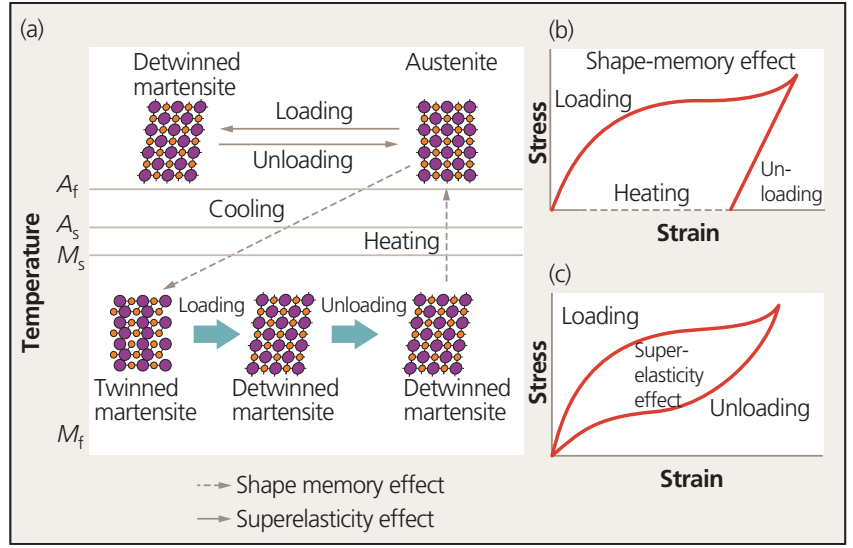

Figure 14. Different phases of shape-memory alloy at different temperatures and their relationship with loading and unloading

low temperatures, for example $-40^{\circ} \mathrm{C}$, and this limits their application in outdoor conditions in cold temperatures (Qiu and Zhu, 2014), whereas copper-based shape-memory alloys can achieve much lower $A_{\mathrm{f}}$, such as $-85^{\circ} \mathrm{C}$, and therefore are suitable for application in construction in an outdoor environment (Qiu and Zhu, 2014; Zhang et al., 2008).

\subsection{Phase-transformation temperatures against working temperature}

To investigate the relationship between phase-transformation and working temperatures, Andrawes and DesRoches (2007) examined the behaviour of bridge restrainers in different ambient temperatures varying from $255 \mathrm{~K}$ to $315 \mathrm{~K}$. With an increase in working temperature, the phase-change stress increases and damping ratios decrease, while the stiffness of the shape-memory alloy restrainers remains the same. For both nickel-titanium and copper-based shape-memory alloys it was found that increased temperatures lead to a reduction in the equivalent damping and an increase in the forward transformation stress.

It is important that shape-memory alloys should be used carefully, particularly when exposed to an outdoor environment and where temperatures vary significantly between different seasons, leading to the shape-memory alloys performing in an unexpected way. Although phase-transformation temperatures are important to consider when using shape-memory alloys in a structure, there are several factors that will affect these, including: (a) composition of the alloys; $(b)$ heat treatment procedure; and $(c)$ mechanical loading. The first two factors are fixed, whereas the last factor will be influenced by the design stress that shape-memory alloys are designed to resist.

Figure 15 demonstrates that as the applied stress increases, the phase-transformation temperatures increase (Lagoudas et al., 2009). Mechanical loading could lead to martensitic transformation, and therefore could lead to a change in phase-transformation temperatures. This is evidenced in a number of researches (Miller and Lagoudas, 2000; Montecinos and Cuniberti, 2008). From previous discussion, the essential development that needs to be achieved is that, should superelasticity of shape-memory alloys be used in construction, manufacturers must be able to develop shape-memory alloys with extremely low $A_{\mathrm{f}}$ ( $\operatorname{such}$ as $-40^{\circ} \mathrm{C}$ ) so that superelasticity can be ensured when needed. 


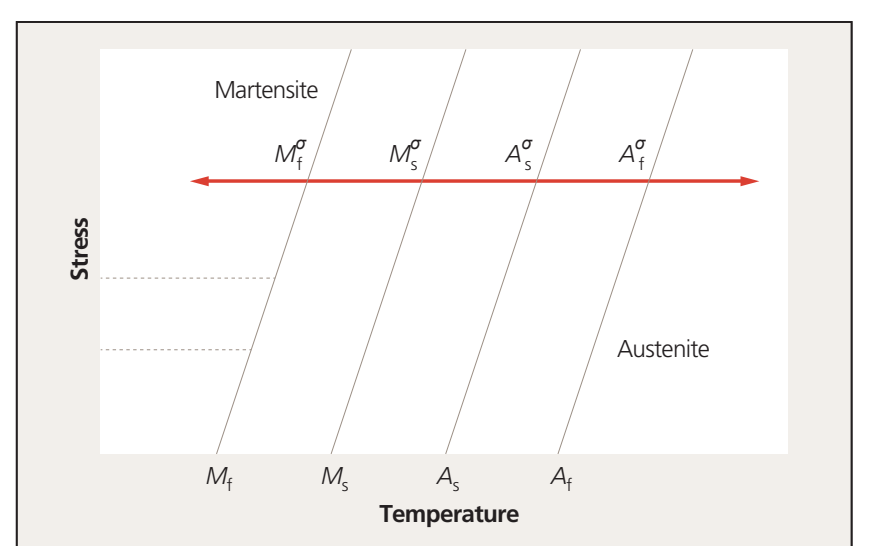

Figure 15. Representation of thermos-mechanical transformation loading path in stress-temperature phase diagram (Lagoudas et al., 2009)

\subsection{Increasing damping of a structure}

The damping capacity of shape-memory alloys comes from two mechanisms: martensite variations reorientation and stress-induced martensitic transformation. The energy-dissipation capacity of nickel-titanium shape-memory alloy wires in the martensite phase is significantly higher than that in the austenite phase (Song et al., 2006).

It was observed that damping capacity is dependent on temperature, loading frequency and number of cycles (Araki et al., 2012; Dolce and Cardone, 2001), and that the energy-dissipation capacity of the shape-memory alloys would be significantly increased when they are prestressed to the martensite phase (Dolce and Cardone, 2001). Prestressing shape-memory alloys before using them in a structure can also provide good energy-dissipation capacity, as shown in Figure 16.

Notice that when the shape-memory alloys are prestressed to the martensite phase, the stiffness of the material will be significantly reduced. It is also important to consider, when using shape-memory alloys to provide damping to dissipate energy, the relationship between phase-transformation and ambient temperatures, in particular for structures built in regions that have extreme weather.

For instance, the shape-memory alloys in a structure could provide good energy-dissipation capacity during a cold winter (for example, $-20^{\circ} \mathrm{C}$ ) but relatively poor energy dissipation in a hot summer $\left(40^{\circ} \mathrm{C}\right)$.

\section{Costs and availability}

One of the main barriers to shape-memory alloys being adopted in construction is the cost of the material, as materials needed in construction tend to be used in large amounts. The cost of producing shape-memory alloys involves the raw materials, processing, heat treatment and machining. To enhance the market uptake of shapememory alloys for use in construction, it is essential to develop low-cost and high-performance shape-memory alloy products.

Shape-memory alloys use a number of metallic commodities for which the price would fluctuate over time, and the price of the shape-memory alloy products are also influenced by shape,

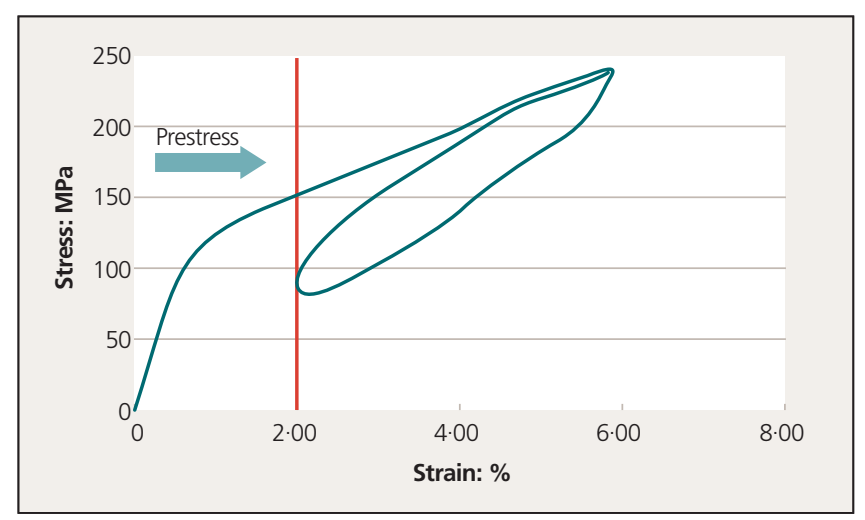

Figure 16. Stress-strain relationship of a copper-based shape-memory alloy bar in tension, the bar was prestressed to martensite phase (2\%) and started to cycle between 2-6\%, which gives much higher energy dissipation

quantities and manufacturing procedure. DesRoches and Smith (2004) pointed out that the price of nickel-titanium shape-memory alloys had decreased from US\$1100 per kilogram in 1999 to US\$111 per kg in 2004.

The retail price of the nickel-titanium shape-memory alloy wire went down to approximately US\$20-30/kg for mass orders as at the end of 2014. The price is expected to decrease over time. This price is only indicative as the price and quality of shape-memory alloy products vary with composition of materials and from manufacturer to manufacturer.

Copper-based shape-memory alloys have recently been developed as an alternative to nickel-titanium shape-memory alloys due to lower cost and superior characteristics (Omori et al., 2013). Araki et al. (2011) pointed out that the material cost of copper-aluminium-manganese shape-memory alloys is about $15-30 \%$ of that of nickel-titanium shape-memory alloys, and when including machining the total cost could be as low as $10 \%$ of that of nickel-titanium shape-memory alloys.

In addition, iron-based shape-memory alloys also share the same low-cost advantages and have better weldability (Cladera et al., 2014; Troiani et al., 2009). Cost analyses have been carried out to compare the cost, loss and downtime after a major earthquake of a ten-storey reinforced-concrete building in Japan (Arup, 2015); the results showed that to add cross-bracing with copper-based shape-memory alloys to the building would increase the total construction cost by $3 \cdot 5 \%$, similar to conventional cross-bracing, whereas that figure would increase to $38.7 \%$ if nickel-titanium shape-memory alloys were used.

The business downtime needed for a shape-memory alloy cross-braced building to recover fully would be reduced by $42 \%$ compared with that of a concrete structure with conventional cross-bracing after a devastating earthquake. In structures with shape-memory alloy bracing, most of the time spent after the earthquake was on repair of non-structural elements, whereas with conventional bracing more time was needed to repair the structure.

Although it appears that nickel-titanium shape-memory alloys are more expensive, the availability is much better than other classes of shape-memory alloy as they have been well developed and have reached a proper market size. A number of well-established manufacturers for nickel-titanium shape-memory alloys can be 
found, while there are only a handful of manufacturers who are at the stage of trying to develop production lines for copper-based and iron-based shape-memory alloys.

The availability of affordable shape-memory alloys with sufficient performance is another barrier to shape-memory alloys being used in building and civil structures.

\section{Fatigue life}

Fatigue of shape-memory alloys can be classified into functional and structural fatigues. The functional fatigue is the decrease in the mechanical function of shape-memory alloys, such as superelasticity and shape-memory effect associated with an increased cyclic loading, whereas the structural fatigue is the accumulated damage in microstructure of shape-memory alloys during cyclic loading and eventually leads to fatigue failure (Eggeler et al., 2004).

There are many factors that influence the fatigue life of shapememory alloys, including loading frequencies, stress levels, phase-transformation temperatures and change in microstructure. Existing research has found that larger stress introduced in shapememory alloys leads to shorter fatigue life.

One particular situation which should be considered when prestressed shape-memory alloys are used in a structure is that the fluctuation in temperature can lead to changes in stress within a shapememory alloy and cause further fatigue failure in the longer term.

\section{Conclusion}

Shape-memory alloys have been successfully used in a number of industries due to their benefits of superelasticity, shape-memory effect and high damping, although the construction sector has not widely adopted this new material due to the limitations of costs, availability and temperature-dependent behaviour described in this paper.

Shape-memory alloys are a rapidly developing material that will become a good option for tackling the challenges that society is now facing, such as natural disaster resilience and demand for high performance. It is essential that engineers and researchers work together to popularise this innovative material's use in building structures and facades as well as in infrastructure.

\section{Acknowledgements}

The work was funded by the International Copper Association (TEK-1079). The authors would like to thank Castellano Maria Gabriella in FIP Industriale, Italy for discussion and sharing her experiences in working with shape-memory alloys, and Arup San Francisco and Tokyo offices for sharing their cost analyses and unpublished report.

\section{References}

Abdulridha A, Palermo D, Foo S and Vecchio FJ (2013) Behavior and modeling of superelastic shape-memory alloy reinforced concrete beams. Engineering Structures 49: 893-904.

Abolmaali A, Treadway J, Aswath P, Lu FK and McCarthy E (2006) Hysteresis behavior of t-stub connections with superelastic shape-memory fasteners. Journal of Constructional Steel Research 62(8): 831-838.
Alam M, Youssef M and Nehdi M (2008) Analytical prediction of the seismic behaviour of super elastic shape-memory alloy reinforced concrete elements. Engineering Structures 30(12): 3399-3411.

Andrawes B and DesRoches R (2005) Unseating prevention for multiple frame bridges using superelastic devices. Smart Materials and Structures 14(3): S60-S67.

Andrawes B and DesRoches R (2007) Effect of ambient temperature on the hinge opening in bridges with shape-memory alloy seismic restrainers. Engineering Structures 29(9): 2294-2301.

Anshuman S (2008) PixelSkin02. See http://nait5.wordpress com/2008/06/11/pixelskin02/ (accessed 22/01/2016).

Araki Y, Endo T, Omori T et al. (2011) Potential of superelastic Cu-Al-Mn alloy bars for seismic applications. Earthquake Engineering and Structural Dynamics 40(1): 107-115.

Araki Y, Maekawa N, Omori T et al. (2012) Rate-dependent response of superelastic $\mathrm{Cu}-\mathrm{Al}-\mathrm{Mn}$ alloy rods to tensile cyclic loads. Smart Materials and Structures 21(3): 032002.

Araki Y, Maekawa N, Shrestha KC et al. (2014) Feasibility of tension braces using Cu-Al-Mn superelastic alloy bars. Structural Control and Health Monitoring 21(10): 1304-1315

Arup (2015) Shape-Memory Alloy Seismic Application to 10-Story Japanese Building - Loss and Downtime Assessment. Arup, San Francisco, CA, USA

Auricchio F, Fugazza D and DesRoches R (2006) Earthquake performance of steel frames with nitinol braces. Journal of Earthquake Engineering 10(1): 45-66.

Bansiddhi A, Sargeant T, Stupp S and Dunand D (2008) Porous nickeltitanium for bone implants: a review. Acta Biomaterialia 4(4): 773-782.

Bellini A, Colli M and Dragoni E (2009) Mechatronic design of a shapememory alloy actuator for automotive tumble flaps: a case study. IEEE Transactions on Industrial Electronics 56(7): 2644-2656.

Benavent-Climent A (2008) Development and application of passive structural control systems in the moderate-seismicity Mediterranean area: the case of Spain. Proceedings of the 14th World Conference on Earthquake Engineering, Beijing, China. See http://www.iitk.ac.in/nicee/ wcee/article/14_S05-02-016.PDF (accessed 22/01/2016).

Chancellor NB, Eatherton MR, Roke DA and Akbaș T (2014) Self-centering seismic lateral force resisting systems: high performance structures for the city of tomorrow. Buildings 4(3): 520-548.

Chang WS, Murakami S, Komatsu K et al. (2013) Potential to use shape memory alloy in timber dowel-type connections. Wood and Fiber Science 45(3): 330-334.

Choi E, Lee DH and Choei NY (2009) Shape-memory alloy bending bars as seismic restrainers for bridges in seismic areas. International Journal of Steel Structures 9(4): 261-273.

Cladera A, Weber B, Leinenbach C et al. (2014) Iron-based shape-memory alloys for civil engineering structures: an overview. Construction and Building Materials 63: 281-293.

Coelho M and Maes P (2009) Shutters: a permeable surface for environmental control and communication. In Proceedings of the 3rd International Conference on Tangible and Embedded Interaction. Association for Computing Machinery, New York, NY, USA, pp. 13-18.

Croci G (2001) Strengthening the basilica of St Francis of Assisi after the September 1997 earthquake. Structural Engineering International 11(3) 207-210.

Das S and Mishra SK (2014) Optimal performance of buildings isolated by shape-memory-alloy-rubber-bearing (shape-memory alloyrb) under random earthquakes. International Journal for Computational Methods in Engineering Science and Mechanics 15(3): 265-276.

DesRoches R and Smith B (2004) Shape-memory alloys in seismic resistant design and retrofit: a critical review of their potential and limitations. Journal of Earthquake Engineering 8(3): 415-429.

DesRoches R, Taftali B and Ellingwood BR (2010) Seismic performance assessment of steel frames with shape-memory alloy connections. Part Ianalysis and seismic demands. Journal of Earthquake Engineering 14(4) 471-486. 
Dezfuli FH and Alam MS (2013) Shape-memory alloy wire-based smart natural rubber bearing. Smart Materials and Structures 22(4): 045013.

Dolce M and Cardone D (2001) Mechanical behaviour of shape-memory alloys for seismic applications 2. Austenite nickel-titanium wires subjected to tension. International Journal of Mechanical Sciences 43(11): 2657-2677.

Dolce M, Cardone D and Palermo G (2007) Seismic isolation of bridges using isolation systems based on flat sliding bearings. Bulletin of Earthquake Engineering 5(4): 491-509.

Effendy E, Liao W, Song G, Mo Y and Loh C (2006) Seismic behavior of low-rise shear walls with shape-memory alloy bars. In Earth \& Space 2006: Engineering, Construction, and Operations in Challenging Environment (Malla RB, Binienda WK and Maji AK (eds)). American Society of Civil Engineers, Reston, VA, USA (CD-ROM)

Eggeler G, Hornbogen E, Yawny A, Heckmann A and Wagner M (2004) Structural and functional fatigue of nickel-titanium shape-memory alloys. Materials Science and Engineering: A 378(1-2): 24-33.

Fang C, Yam MC, Lam AC and Xie L (2014) Cyclic performance of extended end-plate connections equipped with shape-memory alloy bolts. Journal of Constructional Steel Research 94: 122-136.

Hartl D and Lagoudas DC (2007) Aerospace applications of shape-memory alloys. Proceedings of the Institution of Mechanical Engineers, Part G: Journal of Aerospace Engineering 221(4): 535-552.

Hartl D, Lagoudas D, Calkins F and Mabe J (2010a) Use of a Ni60Ti shapememory alloy for active jet engine chevron application: I. Thermomechanica characterization. Smart Materials and Structures 19(1): 015020

Hartl D, Mooney J, Lagoudas D, Calkins F and Mabe J (2010b) Use of a Ni60Ti shape-memory alloy for active jet engine chevron application: ii. Experimentally validated numerical analysis. Smart Materials and Structures 19(1): 015021.

Hu JW, Choi DH and Kim DK (2013) Inelastic behavior of smart recentering buckling-restrained braced frames with superelastic shape-memory alloy bracing systems. Proceedings of the Institution of Mechanical Engineers, Part C: Journal of Mechanical Engineering Science 227(4): 806-818.

Indirli M and Castellano MG (2008) Shape-memory alloy devices for the structural improvement of masonry heritage structures. International Journal of Architectural Heritage 2(2): 93-119

Indirli M, Castellano MG, Clemente P and Martelli A (2001a) Demo-application of shape-memory alloy devices: the rehabilitation of the S. Giorgio Church bell tower. In Proceedings of SPIE's 8th Annual International Symposium on Smart Structures and Materials, Newport Beach, CA, USA. International Society for Optics and Photonics, Bellingham, WA, USA, pp. 262-272.

Indirli M, Forni M, Martelli A et al. (2001b) Further new projects in Italy for the development of innovative techniques for the seismic protection of cultural heritage. Proceedings of the 7th International Seminar on Seismic Isolation, Passive Energy Dissipation and Active Control of Vibrations of Structures, Assisi, Italy.

Johnson R, Padgett JE, Maragakis ME, DesRoches R and Saiidi MS (2008) Large scale testing of nitinol shape-memory alloy devices for retrofitting of bridges. Smart Materials and Structures 17(3): 035018.

Kim B, Lee MG, Lee YP, Kim Y and Lee G (2006) An earthworm-like micro robot using shape-memory alloy actuator. Sensors and Actuators A: Physical 125(2) $429-437$.

Lagoudas D, Miller D, Rong L and Kumar P (2009) Thermomechanical fatigue of shape-memory alloys. Smart Materials and Structures 18(8): 085021

Lignarolo L, Lelieveld C and Teuffel P (2011) Shape morphing windresponsive facade systems realized with smart materials. Proceedings of the International Adaptive Architecture Conference, London, UK.

Loonen R (2015) Bio-inspired adaptive building skins. In Biotechnologies and Biomimetics for Civil Engineering (Pacheco Torgal F, Labrincha JA, Diamanti MV, Yu CP and Lee HK (eds)). Springer, Cham, Switzerland, pp. 115-134.

Ma H, Wilkinson T and Cho C (2007) Feasibility study on a self-centering beamto-column connection by using the superelastic behavior of shape-memory alloys. Smart Materials and Structures 16(5): 1555-1563.

Martelli A (2008) Recent progress of application of modern anti-seismic systems in europe-Part 2: energy dissipation systems, shape-memory alloy devices and shock transmitters. Proceedings of the 14th World Conference on Earthquake
Engineering, Beijing, China. See http://www.iitk.ac.in/nicee/wcee/article/14 S05-02-018.PDF (accessed 22/01/2016).

Massah SR and Dorvar H (2014) Design and analysis of eccentrically braced stee frames with vertical links using shape-memory alloys. Smart Materials and Structures 23(11): 115015.

McCormick J, DesRoches R, Fugazza D and Auricchio F (2007) Seismic assessment of concentrically braced steel frames with shape-memory alloy braces. Journal of Structural Engineering 133(6): 862-870.

Miller DA and Lagoudas DC (2000) Thermomechanical characterization of nickeltitaniumCu and nickel-titanium shape-memory alloy actuators: influence of plastic strains. Smart Materials and Structures 9(5): 640-652.

Montecinos S and Cuniberti A (2008) Thermomechanical behavior of a CuAlBe shape-memory alloy. Journal of Alloys and Compounds 457(1-2): 332-336.

Morgan N (2004) Medical shape-memory alloy applications-the market and its products. Materials Science and Engineering: A 378(1-2): 16-23.

Omori T, Ando K, Okano M et al. (2011) Superelastic effect in polycrystalline ferrous alloys. Science 333(6038): 68-71.

Omori T, Kusama T, Kawata S et al. (2013) Abnormal grain growth induced by cyclic heat treatment. Science 341(6153): 1500-1502.

Ozbulut OE and Hurlebaus S (2010) Evaluation of the performance of a slidingtype base isolation system with a nickel-titanium shape-memory alloy device considering temperature effects. Engineering Structures 32(1): 238-249.

Ozbulut OE and Hurlebaus S (2011) Seismic assessment of bridge structures isolated by a shape-memory alloy/rubber-based isolation system. Smart Materials and Structures 20(1): 015003

Qin CJ, Ma PS and Yao Q (2004) A prototype micro-wheeled-robot using shapememory alloy actuator. Sensors and Actuators A: Physical 113(1): 94-99.

Qiu CX and Zhu S (2014) Characterization of cyclic properties of superelastic monocrystalline Cu-Al-Be shape-memory alloy wires for seismic applications. Construction and Building Materials 72: 219-230.

Rofooei $F$ and Farhidzadeh A (2011) Investigation on the seismic behavior of steel mrf with shape-memory alloy equipped connections. Procedia Engineering 14 3325-3330.

Saiidi MS and Wang $\mathrm{H}$ (2006) Exploratory study of seismic response of concrete columns with shape-memory alloys reinforcement. ACI Structural Journal 103(3): 435-442.

Song G, Ma N and Li HN (2006) Applications of shape-memory alloys in civil structures. Engineering Structures 28(9): 1266-1274.

Soroushian P, Ostowari K, Nossoni A and Chowdhury H (2001) Repair and strengthening of concrete structures through application of corrective posttensioning forces with shape-memory alloys. Transportation Research Record 1770: 20-26.

Stoeckel D (1990) Shape-memory actuators for automotive applications. Materials \& Design 11(6): 302-307.

Sun L, Huang WM, Ding Z et al. (2012) Stimulus-responsive shape-memory materials: a review. Materials \& Design 33: 577-640.

Tashakori M (2014) Design of a Computer Controlled Sun-Tracking Facade Model. MSc thesis, The Pennsylvania State University, State College, PA, USA.

Troiani H, Sade M, Bertolino G and Baruj A (2009) Martensitic transformation temperatures and microstructural features of FeMnCr alloys. In ESOMAT 2009 - 8th European Symposium on Martensitic Transformations (Šittner P, Paidar V Heller L and Seiner H (eds)). EDP Sciences, Les Ulis, France, paper 06002.

Wang Z, Hang G, Li J, Wang Y and Xiao K (2008) A micro-robot fish with embedded shape-memory alloy wire actuated flexible biomimetic fin. Sensors and Actuators A: Physical 144(2): 354-360.

Wilde K, Gardoni P and Fujino Y (2000) Base isolation system with shapememory alloy device for elevated highway bridges. Engineering Structures 22(3): 222-229.

Yam MC, Fang C, Lam AC and Zhang Y (2015) Numerical study and practical design of beam-to-column connections with shape-memory alloys. Journal of Constructional Steel Research 104: 177-192.

Zhang Y, Camilleri JA and Zhu S (2008) Mechanical properties of superelastic CuAl-Be wires at cold temperatures for the seismic protection of bridges. Smart Materials and Structures 17(2): 025008 